\title{
Pneumomédiastin compliquant un asthme aigu
}

\section{Pneumomediastinum associated with acute asthma}

\section{Delarbre $\cdot$ A. Depil-Duval}

Reçu le 23 mars 2013; accepté le 15 mai 2013

(C) SFMU et Springer-Verlag France 2013

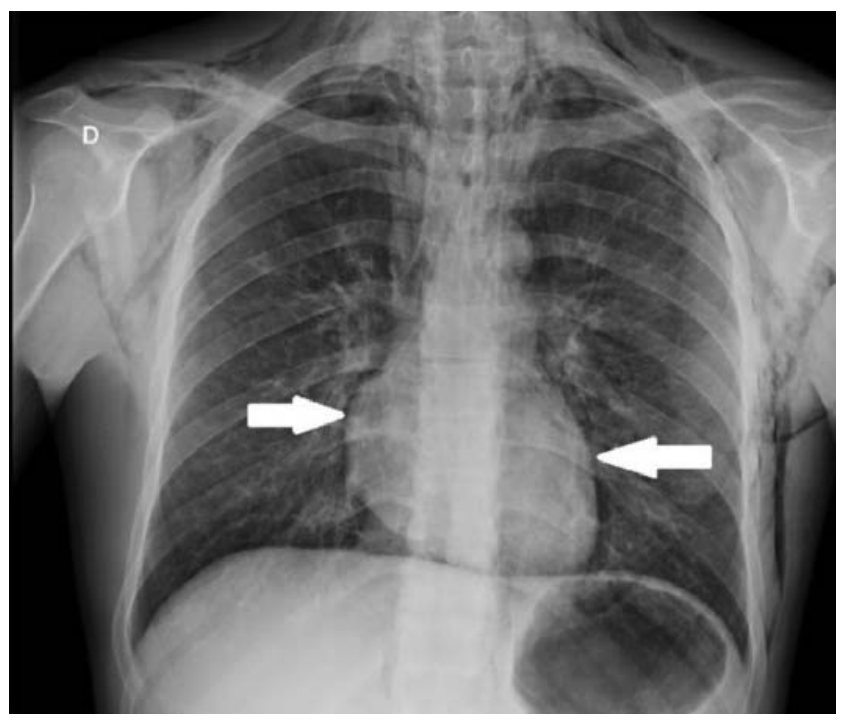

Fig. 1 Radiographie thoracique de face ; l'hyperclarté en liseré bordant les arcs médiastinaux bilatéraux correspond au pneumomédiastin

Un patient de 19 ans aux antécédents d'asthme persistant modéré se présente aux urgences pour dyspnée aiguë avec sibilants, toux et sensation de gène douloureuse de la région cervicale. L'examen révèle une tuméfaction de la base du cou avec rubéfaction des téguments visibles tête en extension avec un emphysème sous-cutané sus-claviculaire bilatéral. La radiographie pulmonaire (Fig. 1) établit le diagnostic. Le scanner thoracique confirme la présence d'un pneumomédiastin associé à un emphysème sous-cutané cevicothoracique et à un pneumothorax bilatéral de très faible abondance

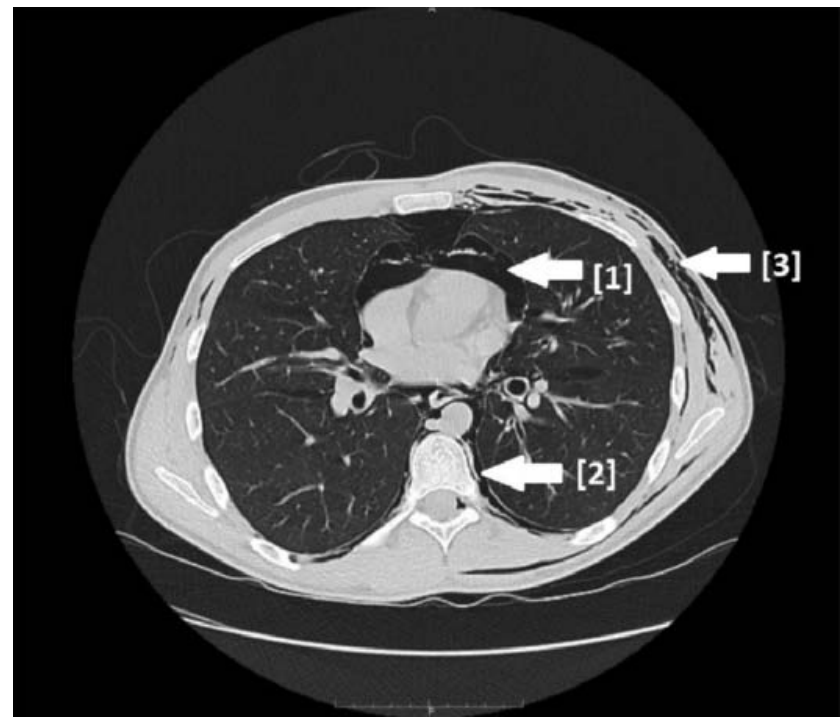

Fig. 2 Scanner thoracique non injecté montrant le pneumomédiastin [1], le pneumothorax [2] et l'emphysème sous-cutané [3]

(Fig. 2). Hémodynamiquement stable, le patient a bénéficié d'une surveillance en unité de soins continus, de bronchodilatateurs de courte durée d'action. Le pneumomédiastin est une complication rare de la crise d'asthme aiguë, loin derrière le pneumothorax, de mécanisme proche. Le diagnostic est rapidement établi sur la radiographie thoracique par les hyperclartés évocatrices et l'emphysème sous-cutané. La prise en charge dépend des comorbidités et des facteurs de risques ; pour ce jeune patient en bonne santé, elle s'est limitée à une surveillance de 24 heures en surveillance continue.

D. Delarbre · A. Depil-Duval $(\bowtie)$

Service d'accueil des urgences, CHI Eure-Seine, F-27000 Evreux e-mail : Arnaud.Depil-Duval@chi-eureseine.fr 